Article

\title{
Synthesis and Characterization of Mechanically Alloyed, Nanostructured Cubic MoW Carbide
}

\author{
Martin Martinez Ruiz ${ }^{1}$, Jesús Noé Rivera Olvera ${ }^{2, *} \mathbb{D}$, Rodolfo Morales Davila ${ }^{1,3}$, \\ Leonardo González Reyes ${ }^{4}{ }^{\mathbb{D}}$, Vicente Garibay Febles ${ }^{5}{ }^{\circledR}$, Jesus Garcia Martinez ${ }^{2}$ \\ and Lucía G. Diaz Barriga Arceo ${ }^{1, *}$ \\ 1 Department of Metallurgy, Instituto Politécnico Nacional-ESIQIE, Ed. 7 Zacatenco, \\ Ciudad de México C.P. 07738, Mexico; mruiz913.mr@gmail.com (M.M.R.); rmorales@ipn.mx (R.M.D.) \\ 2 Tecnológico Nacional de México, Campus Ixtapaluca, TESI, Km. 7 de la carretera Ixtapaluca-Coatepec s/n, \\ Ixtapaluca, Estado de México C.P. 56580, Mexico; jesusgarciamtz@tesi.edu.mx \\ 3 K \& E Technologies, Manizales 88, Residencial Zacatenco, Del. Gustavo A. Madero, \\ Ciudad de México C.P. 07369, Mexico \\ 4 Universidad Autónoma Metropolitana-Azcapotzalco Av. San Pablo 180, Col. Reynosa Tamaulipas, \\ Ciudad de México C.P. 02200, Mexico; lgr@correo.azc.uam.mx \\ 5 Instituto Mexicano del Petróleo, Eje Central Lázaro Cárdenas Norte 152, San Bartolo Atepehuacan, \\ Ciudad de México C.P. 07730, Mexico; vgaribay@imp.mx \\ * Correspondence: jnoe.rivera@tesi.edu.mx (J.N.R.O.); luchell@yahoo.com (L.G.D.B.A.)
}

Received: 4 December 2020; Accepted: 14 December 2020; Published: 20 December 2020

\begin{abstract}
Carbides are used extensively as cutting tools, forming dies, and recently in catalysis applications, among other industrial applications. In this work, the synthesis and characterization of a nanostructured MoW bimetallic carbide were carried out by mechanical alloying with a mixture of elemental powders with a nominal composition of $\mathrm{W}_{1.5} \mathrm{Mo}_{6} \mathrm{C}_{2.5}$ at different grinding times as follows: 25, 50, and $75 \mathrm{~h}$ in a low-energy ball mill at a speed of $500 \mathrm{rpm}$ and 125 and $150 \mathrm{~h}$ in a high-energy ball mill at a speed of $1500 \mathrm{rpm}$. The formation of a solid solution was observed at $150 \mathrm{~h}$ of milling; the nanostructured bcc MoW carbide corresponded to the main phase in the sample, besides the presence of the nanostructured MoW alloy as a secondary phase with an average crystal size of $40.8 \mathrm{~nm}$. The phases and morphology at every stage of milling were studied by: X-ray diffraction (XRD), scanning electron microscopy (SEM), high-resolution transmission electron microscopy (HRTEM), and Vickers hardness. As the milling time increased, the hardness of these particles increased from 10.5 to $31.48 \mathrm{GPa}$ for the powder particles milled for $150 \mathrm{~h}$. The samples obtained at 125 and $150 \mathrm{~h}$ of milling were evaluated during catalytic aqua-thermolysis of heavy oil to analyze fuel desulfurization properties by Fourier transform infrared (FTIR) techniques. The results showed the breaking of S-S bonds, indicating the existence of a desulfurization reaction of heavy oil.
\end{abstract}

Keywords: mechanical alloying; nanocrystalline materials; bimetallic carbide; X-ray diffraction; MEB; HRTEM

\section{Introduction}

Over the last few years, there has been increasing interest in the exploration of production methods for nanostructured materials because their physical properties change as the crystallite particle size decreases. There are new features in the electronic structure at nanosized scales, which are sensitive to the properties of the materials' constituent elements. The presence of carbon yields excellent mechanical and catalytic properties, mainly when the carbon is mixed or used to support transition metals [1-3]. An example of these kinds of materials is NiW, MoW, and NiMoW phases, which have 
attracted attention by the petrochemical industry due to their applications as catalysts in extra-heavy desulfurization crudes. These systems are cheaper than other catalysts for the same purpose [4]. Previous research showed that MoW and NiW systems combined with carbon to produce carbides and compounds compete against other mechanically reinforced materials by adding elements like $\mathrm{Al}_{2} \mathrm{O}_{3}$ and $\mathrm{ZrO}_{2}$ composites; even their performance is comparable to multiwall carbon nanotubes (MWCNTs) [5-9]. Another advantage of these materials is that the formation of bulk materials from transition metal carbide powders is feasible since sintering performs under friendly conditions [10]. Besides, currently, Mo- and W-based materials are being analyzed as dielectrics with good capacity for storage and processing of thermal and electrical energy [10].

Only a few studies in the literature analyzed the formation and microstructural evolution of the MoW phase as an alloy and the transformation of bimetallic carbides of those metals, such as the change from MoW to MoWC. This condition is because the synthesis methods are costly or involve chemical reactions at very high temperatures [7,11-14]. However, this situation has changed since new production methods are now available. For example, Wiedemann et al. reported a MoW solid solution with polycrystalline single-phase microstructure produced by mechanosynthesis, but the authors did not mention the resultant crystalline structure produced after the solid solution during mechanical alloying (MA) [15]. Later Wu et al. synthesized nanocrystalline W-based powder particles; their results showed that with mechanical milling, they increased high-density crystalline defects that make them suitable as alloys in systems that are complicated to produce by other conventional synthesis methods [10]. Mechanical alloying (MA) is a solid-state technique involving repeated particle fracture that can be processed through high- or low-energy ball mills. It is a versatile and low-cost process for synthesizing super-saturated phase nanopowders, solid solutions, nanocrystalline materials, and immiscible systems [16,17]. For example, a recent study by Chen et al. found the formation of a solid solution in a full range of compositions by the sol-gel method combined with hydrogen reduction [11]. The MA method has the advantage that it can produce a powder with nanoscale particles in large quantities compared with other methods like the sol-gel $[3,18,19]$. These findings demonstrate that MA may be a useful approach in producing nanostructured carbides, making them optimal for heavy crude oil desulfurization applications during catalytic aqua-thermolysis [20].

Other studies report MoWC phase production only in a hexagonal crystalline structure at high pressure or temperature [21,22]. However, there are no reports about the production of MoWC alloys with a bcc crystalline structure even when Haag rules predict their existence [23]. Hence, additional work is necessary to understand the phase transformation from Mo and $\mathrm{W}$ to MoW and MoWC. In this work, there were two goals; first, the synthesis and study of the microstructural evolution of an MoW carbide, reported previously in another work, where there was no mention of the crystalline structure in this catalyst [7], and then there was the need to study the conditions of producing MoW and MoWC phases by MA, including composition and energy requirements. The second goal was to study the stability and composition of the synthesized MoW phase by a thermodynamic analysis using the Miedema model [24], not reported in the literature for this phase. This model allows calculating the formation of a solid solution of an amorphous phase under atmospheric conditions during MA. Even though MA is not an equilibrium process, studies suggest that the Miedema model can predict the stability of MA product [17] because this model is a semi-empirical approach to estimate heat formation of metal alloys and compounds. Additionally, the evolution of microhardness at different grinding times allowed to prove the transformation from MoW to MoWC. The catalytic properties on desulfurization of UTSIL heavy oil during catalytic aqua-thermolysis were reported as an application of interest for this material. 


\section{Materials and Methods}

\subsection{Synthesis}

The first step was the preparation of a mixture made of pure elemental powders of graphite (C), tungsten (W), and molybdenum (Mo), with the nominal composition on a weight percent basis of $\mathrm{W}_{1.5} \mathrm{Mo}_{6} \mathrm{C}_{2.5}$. A stainless-steel container held this mixture under an inert atmosphere (Ar), with zirconia oxide media milling of different sizes $(1 / 2 \times 1 / 2$ inch and $3 / 8 \times 3 / 8$ inch) at a ratio in weight of 10:1 balls/powder. The processing of the mixture was through mechanical alloying techniques for times of 25, 50, 75, 125, and $150 \mathrm{~h}$ in two energy processes: low-energy (Heiko, TI-100, Fukushima, Japan) and high-energy (Spartan Fritsch, Sylacauga, AL, USA) ball mills at 500 and 1500 rpm, respectively. The use of two kinds of milling machines was necessary to obtain a unique phase.

\subsection{Structural Analysis}

The microstructural characterization included the use of a Bruker A.X.S. D8 Focus diffractometer (Bruker, Karlsruhe, Germany), with CuK $\alpha$ radiation $\left(\lambda=1.5406 \AA\right.$ ) operated in a range $2 \theta$ of $10-110^{\circ}$ at a speed of $4^{\circ} / \mathrm{min}$. The X-ray diffraction (XRD) pattern identification was through the International Center for Diffraction Data (ICDD) database PDF-2(2003). The analysis of sample microstructures was through scanning electron microscopy (SEM) with a JEOL JSM 6701F (JEOL, Tokyo, Japan) microscope. High-resolution transmission electron microscopy (HRTEM) complemented microstructure characterization through an F.E.I. Tecnai G-20 microscope at $200 \mathrm{kV}$ (FEI-Titan Microscope, Hillsboro, OR, USA). The DigitalMicrograph software calculated d-spacing from HRTEM images.

The Vickers microhardness evaluation was through a compacted sample of mechanically alloyed powder particles inserted on a stainless-steel die using a 3 ton press to obtain a cylinder with dimensions of $10 \mathrm{~mm} \times \$ 30 \mathrm{~mm}$. The microhardness of the samples was measured by using the FM microhardness tester (Future-Tech, Kanagawa, Japan) using a diamond indenter applying loads of 2 ton for $10 \mathrm{~s}$. The indentations involved three parallel lines with three points each and the average values for every sample. The average microhardness included different milling times.

\subsection{Desulfurization Analysis}

The evaluation of the processed material's desulfurization capacity used a catalytic aqua-thermolysis technique and extra-heavy crude UTSIL. To continue, an emulsion made of crude and seawater prepared at a 1:1 ratio (crude:water) and $1 \%$ by weight of powder particles as the catalyst was available. The catalytic aqua-thermolysis evaluation was for $24 \mathrm{~h}$ at a temperature of $200{ }^{\circ} \mathrm{C}$. These reaction parameters were the object of an optimization procedure in preliminary tests. A Perkin Elmer Spectrum Two UAT-IR spectrometer (Perkin, MA, USA) helped to identify the vibration bond reaction changes during the catalytic performance to evaluate UTSIL heavy oil desulfurization.

\section{Results and Discussion}

\subsection{Structural and Morphological Properties of the Power Particles}

\subsubsection{X-ray Diffraction}

Figure 1 shows the $X$-ray diffraction results of the powder particles after 25, 50, and $75 \mathrm{~h}$ at $500 \mathrm{rpm}$ in a low-energy ball mill. The peak with the highest intensity corresponded to the graphite (002) plane. When grinding time increased, the (002) graphite peak decreased in the XRD spectrum after 25-50 $\mathrm{h}$ of milling. This decrease corresponded to a $62.71 \%$ reduction of the peak intensity, and from 50 to $75 \mathrm{~h}$, a reduction of $45.14 \%$ of intensity. By increasing the milling time, all the peaks decreased; this is related to the microstructural refinement and the formation of crystallographic defects caused by mechanical impacts during the MA process. These events allow the formation of new phases. The synthesis of the 
MoW phase can form a solid solution for different compositions and temperatures [12]. Section 3.1.2 explains more in detail the thermodynamic calculation of the formation of this solid solution phase.

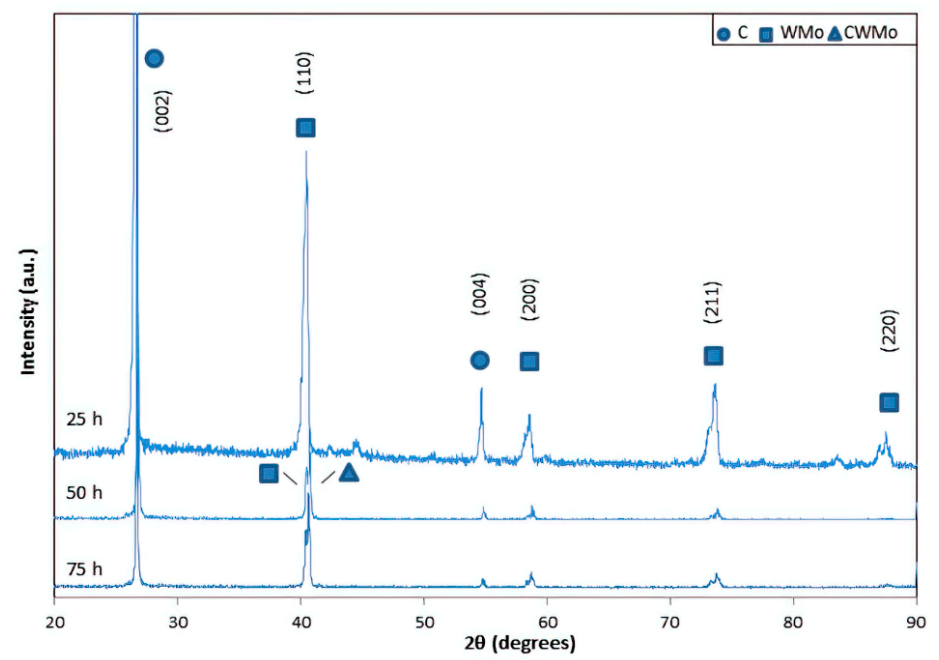

Figure 1. X-ray diffraction (XRD) patterns of the MoWC mixture at different grinding times at $500 \mathrm{rpm}$ of a low-energy ball mill.

The formation of the MoW solid solution phase is possible when Hume-Rothery rules are satisfied as follows: (1) Size factor: $\mathrm{W}$ and Mo atoms should be of similar size (with no more than $15 \%$ difference in their atomic radii). The atomic radii of $W$ and Mo are $0.1386 \mathrm{~nm}$ and $0.1394 \mathrm{~nm}$ [25], respectively, with a size difference of $0.57 \%$; this is a much smaller value than $15 \%$. (2) Crystal structure: The raw materials must have the same crystal structure; in this case, both materials show a bcc crystalline structure. (3) Valence: Atoms must have the same valence; in this case, both elements show valences of 2, 3, 4, 5, and 6. According to this previous explanation, the MoW solid solution phase is feasible through MA. The MoW alloy was indexed with the characteristic peak of this phase at $40.46^{\circ}$, a value that coincides perfectly with the $071-9828$ JCPDS card. However, at 50 and $75 \mathrm{~h}$ of milling, a new peak of greater intensity located between $40.6^{\circ}$ and $40.8^{\circ}$ was observed (shown in Figure 2). This phenomenon was related to the decreasing of (002) peak (graphite phase) caused by the introduction of carbon to the MoW lattice to produce the MoWC bimetallic nanostructured carbide in a solid solution.

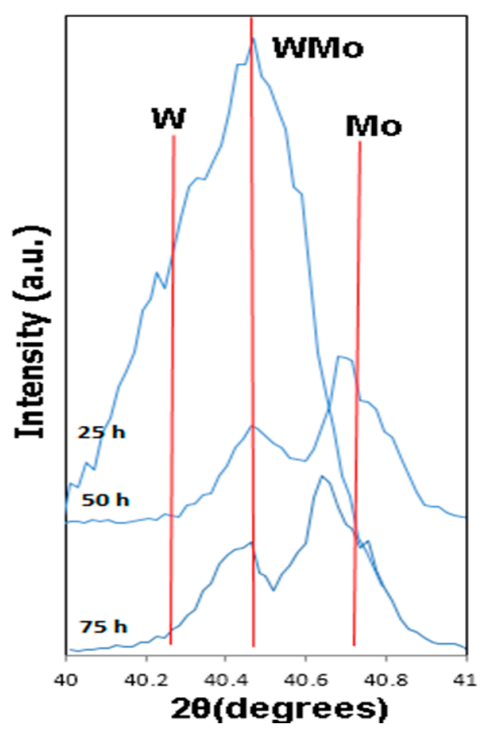

Figure 2. A zoom between $40^{\circ}$ and $41^{\circ}$ of XRD patterns of the MoWC mixture at different grinding times in a low-energy mill. 
One advantage of using a low-energy ball mill is that this process can produce a small amount of cross contamination caused by media milling and vial [17]. Nevertheless, to transform the elemental powder particles to the nanostructured carbide phases in a solid solution, at least, it needs between 120 and $240 \mathrm{~h}$ in this kind of process (low energy) [7,26]. As observed in Figure 1, a low-energy ball mill was not enough to introduce a major quantity of carbon into the MoW lattice, so it needed a longer milling time to transform Mo, $\mathrm{W}$, and C elemental materials to the MoWC phase. To avoid extended milling times until $240 \mathrm{~h}$, the use of a high-energy ball mill at $1500 \mathrm{rpm}$ was an option to produce the MoW nanostructured bimetallic carbide. Figure 3 shows the $\mathrm{X}$-ray diffraction of the powder particles by a high-energy ball mill at 125 and $150 \mathrm{~h}$. The intensity of the peak corresponding to the graphite (002) showed a drastic decrease from 125 to $150 \mathrm{~h}$ of milling, which corresponded to a $99.74 \%$ reduction. This behavior was attributed to the incorporation of $C$ into the MoW matrix, occupying the interstitial sites, thus producing the $\mathrm{WMoC}$ bimetallic carbide of the interstitial solid solution due to the increasing of (110) plane with a value of $42.44 \%$ between 125 and $150 \mathrm{~h}$ of milling.

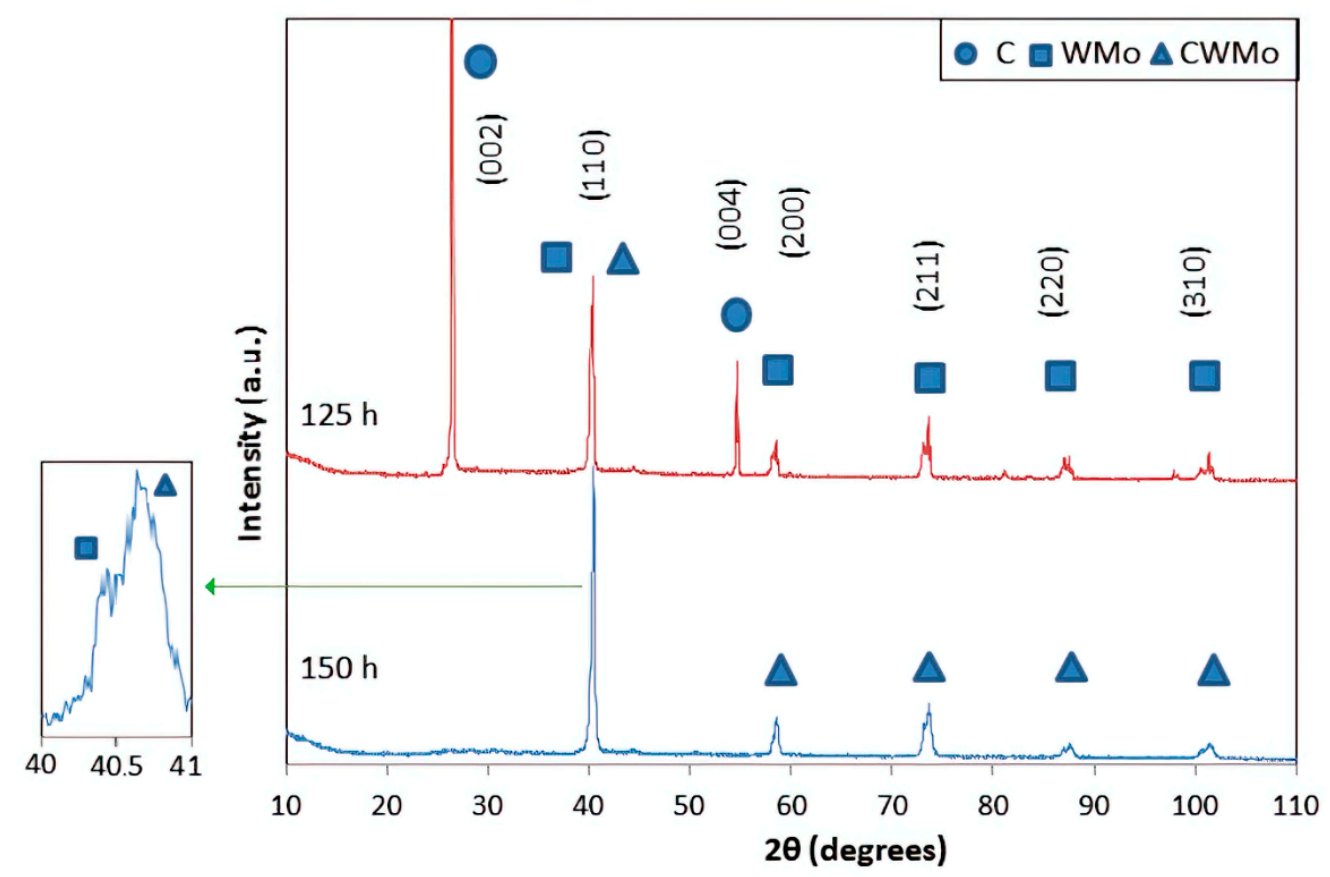

Figure 3. XRD patterns of the MoWC mixture at different grinding times in a high-energy mill $(1500 \mathrm{rpm})$ and a zoom between $40^{\circ}$ and $41^{\circ}$ of XRD patterns of the MoWC mixture at $150 \mathrm{~h}$ of milling.

Modeling the interstitial atom as a hard sphere, it yields that the radius ratio of the interstitial atom/radius of the host metal atom must be less than 0.59 for an interstitial structure [25]. The atomic radius of graphite is $0.067 \mathrm{~nm}$, in which the $\mathrm{C} / \mathrm{W}$ and C/Mo ratios are 0.4806 and 0.4834 , respectively, indicating that graphite can accommodate in the interstitial sites of the WMo metal lattice. The two-metal lattice has a bcc crystalline structure. In this type of structures, there are two types of interstitial sites: tetrahedral sites, located at $\frac{1}{2}, \frac{1}{4}$, and 0 (real space with all equivalent sites) and octahedral sites, located on the faces of the cube at $\frac{1}{2}, 0$, and $\frac{1}{2}$ (real space with all equivalent sites). An atom whose radius relation is greater than 0.414 is in an octahedral site [27]. For the transition elements, the metallic structure's interstitial tetrahedral sites are very small to accommodate graphite, so only the octahedral sites must be occupied [23]. At $150 \mathrm{~h}$ of milling, the MoWC phase remained with the largest intensity, and the WMo phase was still present at this stage of milling (see the zoomed-in image at $150 \mathrm{~h} \mathrm{in}$ Figure 3). The microstructural evolution sequence of the phase against milling time was:

$$
\mathrm{C}+\mathrm{W}+\mathrm{Mo} \rightarrow \mathrm{C}+\mathrm{WMo} \rightarrow(\mathrm{WMo}) \mathrm{C}
$$


We proposed that this phase (MoWC) showed a bcc crystalline structure like MoW system; this agreed with the experimental method proposed by Suryanarayana for the determination of crystalline structures of cubic type, which explains that the correct Bravais lattice can be determined following the sequence of the typical reflections associated with the cubic lattice [26] from the relation:

$$
\sin ^{2} \theta=\frac{\lambda}{4 a^{2}}\left(h^{2}+k^{2}+l^{2}\right)
$$

After calculating for the material, the sequence path of reflections for $h^{2}+k^{2}+l^{2}$ was $2,4,6,8$, and 10, which corresponded to a bcc structure; the indexation of crystallographic planes was: (110), (200), (211), (220), and (310) (see Figure 3). The calculation of the lattice parameter and d-spacing was according to Equations (1)-(3) and every plane assignment for each reflection was associated with the lattice parameter/d-spacing ratio. The results are in Table 1.

$$
\begin{gathered}
d=\frac{\lambda}{2 \sin \theta} \\
a=d\left(h^{2}+k^{2}+l^{2}\right)
\end{gathered}
$$

where $d$ is the interplanar distance (nm), $a$ is the lattice parameter (nm), and $\lambda=0.1540 \mathrm{~nm}$.

Table 1. Crystal lattice parameter in the MoWC system.

\begin{tabular}{ccccccc}
\hline Line & $\boldsymbol{h}$ & $\boldsymbol{k}$ & $\boldsymbol{l}$ & $\boldsymbol{h}^{\mathbf{2}}+\boldsymbol{k}^{\mathbf{2}}+\boldsymbol{l}^{\mathbf{2}}$ & $\boldsymbol{a}_{\mathbf{0}}(\mathrm{nm})$ & $\boldsymbol{d}_{\boldsymbol{h k l} \boldsymbol{l}}(\mathrm{nm})$ \\
\hline 1 & 1 & 1 & 0 & 2 & 0.3149 & 0.2227 \\
2 & 2 & 0 & 0 & 4 & 0.3149 & 0.1575 \\
3 & 2 & 1 & 1 & 6 & 0.3149 & 0.1285 \\
4 & 2 & 2 & 0 & 8 & 0.3147 & 0.1113 \\
5 & 3 & 1 & 0 & 10 & 0.3146 & 0.0995 \\
\hline
\end{tabular}

An average lattice parameter of $0.3148 \mathrm{~nm}$ was obtained. According to XRD results and Scherrer calculations, at $150 \mathrm{~h}$ of milling, the crystal size showed an average of about $40.8 \mathrm{~nm}$. This indicated that the formation of the MoW alloy and the bcc structure of MoWC was only possible at the nanostructure level. The material showed a solid solution behavior at this size, and the crystallinity was of a short-range order $[17,28]$. According to Cottrel [29], there are solid solutions with several components, where the primary phase shows the majority weight percent, and the others are formed with intermediate ranges of the composition. In this case, the phase observed at $150 \mathrm{~h}$ was a nanostructured MoW alloy that could be considered as a secondary solid solution. This implied that these phases require very high energy for their formation. The evidence that this material had a solid solution behavior is easily observed in Sections 3.1.4 and 3.2, which will be discussed later.

\subsubsection{Thermodynamic Analysis for MoW Synthesis during Mechanical Alloying}

MoW was the first phase formed during the first stage of milling. To study the stability of the MoW phase and the production of MoW during MA, free energy $\Delta G$ according to the Miedema model for amorphous and solid solutions was calculated from a mixture of Mo and W pure elements using:

$$
\Delta G=\Delta H-T \Delta S
$$

where $\Delta H$ and $\Delta S$ are the enthalpy and entropy of mixing, respectively, and $T$ is the temperature at which a solid solution is formed $[24,30]$. For MoW solid solution formation from the initial powders, $\Delta S$ is on line with the assumption of an ideal configurational entropy of mixing:

$$
\Delta S^{\mathbf{M o}, \mathbf{W}}=-R\left(x_{\mathrm{Mo}} \ln x_{\mathrm{Mo}}+x_{\mathrm{W}} \ln x_{\mathrm{W}}\right)
$$


where $R$ is the universal gas constant $\left(8.3144 \mathrm{~J} \mathrm{~K}^{-1} \mathrm{~mol}^{-1}\right)$ and $x_{\mathrm{Mo}}$ and $x_{\mathrm{W}}$ are the mole fractions of Mo and $\mathrm{W}$ elements, respectively. The enthalpy of formation of an MoW solid solution consists of three terms [31]:

$$
\Delta H^{\mathbf{M o}, \mathbf{w}}=\Delta H_{\text {chem }}+\Delta H_{\text {struct }}+\Delta H_{\text {elas }}
$$

where $\Delta H_{\text {chem }}, \Delta H_{\text {struct }}$, and $\Delta H_{\text {elas }}$ are the chemical, structural, and elastic contributions due to mixing atoms, size mismatch, and the difference of valence electrons and crystal structure of the solute and solvent atoms, respectively. $\Delta H_{\text {chem }}$ is given as:

$$
\Delta H_{\text {chem }}=\frac{2 f\left(C^{S}\right) x_{\mathrm{Mo}} V_{\mathrm{Mo}}^{2 / 3} x_{\mathrm{W}} V_{\mathrm{W}}^{2 / 3}}{\left[\left(n_{w s}^{\mathrm{Mo}}\right)^{-1 / 3}+\left(n_{w s}^{\mathrm{W}}\right)^{-1 / 3}\right]\left[x_{\mathrm{Mo}} V_{\mathrm{Mo}}^{2 / 3}+x_{\mathrm{W}} V_{\mathrm{W}}^{2 / 3}\right]} \times\left[-P(\Delta \vartheta *)^{2}+Q\left(\Delta n_{w s}\right)^{2 / 3}\right]
$$

where $n_{w s}, V$, and $\vartheta^{*}$ are the electron density, molar volume, and work function of the elements Mo and $\mathrm{W}$, respectively. $P$ and $Q$ are experimental constants, where the first $(P)$ metal is a transition metal (Mo) and the second is $Q=9.4 P$ for $\mathrm{W}$; then, the values of $P$ and $Q$ are 12.8 and 120.32, respectively [32]. $f\left(C^{S}\right)$ Equation (8) is the concentration function for solid solutions, and it can be calculated by the following equation:

$$
f\left(C^{S}\right)=\left(\frac{x_{\mathrm{Mo}} V_{\mathrm{Mo}}^{2 / 3}}{x_{\mathrm{Mo}} V_{\mathrm{Mo}}^{2 / 3}+x_{\mathrm{W}} V_{\mathrm{W}}^{2 / 3}}\right)\left(\frac{x_{\mathrm{W}} V_{\mathrm{W}}^{2 / 3}}{x_{\mathrm{Mo}} V_{\mathrm{Mo}}^{2 / 3}+x_{\mathrm{W}} V_{\mathrm{W}}^{2 / 3}}\right)
$$

Then, by substituting the concentration function in (7), $\Delta H_{\text {chem }}$ is calculated as:

$$
\Delta H_{\text {chem }}=\frac{2 x^{2}{ }_{\mathrm{Mo}} V_{\mathrm{Mo}}^{4 / 3} x^{2}{ }_{\mathrm{W}} V_{\mathrm{W}}^{4 / 3}}{\left[\left(n_{w s}^{\mathrm{Mo}}\right)^{-1 / 3}+\left(n_{w s}^{\mathrm{W}}\right)^{-1 / 3}\right]\left[x_{\mathrm{Mo}} V_{\mathrm{Mo}}^{2 / 3}+x_{\mathrm{W}} V_{\mathrm{W}}^{2 / 3}\right]^{3}} \times\left[-P(\Delta \vartheta *)^{2}+Q\left(\Delta n_{w s}\right)^{2 / 3}\right]
$$

The elastic contribution of enthalpy $\Delta H_{\text {elast }}$ is calculated as:

$$
\Delta H_{\text {elast }}=x_{\mathrm{Mo}} x_{\mathrm{W}}(x_{\mathrm{Mo}} \underbrace{\frac{2 K_{\mathrm{Mo}} G_{\mathrm{W}}(\Delta V)^{2}}{3 K_{\mathrm{Mo}} V_{\mathrm{W}}+4 G_{\mathrm{W}} V_{\mathrm{Mo}}}}_{\Delta E_{\mathrm{Mo} \mathrm{in}}}+x_{\mathrm{W}} \underbrace{\frac{2 K_{\mathrm{W}} G_{\mathrm{Mo}}(\Delta V)^{2}}{3 K_{\mathrm{W}} V_{\mathrm{Mo}}+4 G_{\mathrm{Mo}} V_{\mathrm{W}}}}_{\Delta E_{\mathrm{W}} \text { in Mo }})
$$

where $\Delta E_{\mathrm{Mo}}$ in $\mathrm{W}$ and $\Delta E_{\mathrm{W}}$ in Mo are the elastic energies caused by Mo dissolving in $\mathrm{W}$ and $\mathrm{W}$ dissolving in Mo, respectively. $K$ and $G$ are the bulk and shear moduli, respectively. The structure contribution of enthalpy is related to the fact that transition metals show preferential crystallization in one of three simple crystallographic phases (bcc) depending on the number of valence electrons $\mathrm{Z}$ (summation of $s$ and $d$ electrons) [24]. $\Delta H_{\text {struct }}$ is a small positive value, and it can be neglected in the estimation of the enthalpy of mixing [32]. For the case of an amorphous phase, since there is no crystal structure and the atoms can arrange themselves in such a manner that mismatch is avoided, the elastic and structural enthalpies can be neglected [32]. The enthalpy of the amorphous phase can be obtained as follows:

$$
\Delta H_{\text {amorphous }}=\Delta H_{\text {chem }}+\beta T_{f}
$$

where $T_{f}=x_{\mathrm{Mo}} T m^{M o}+x_{\mathrm{W}} T m^{W}$ and $\beta=0.0035 \mathrm{~kJ} \mathrm{~mol}^{-1} \mathrm{~K}^{-1} . T_{m}$ is the melting temperature of the raw materials (Mo and $\mathrm{W}$ ). The parameters to obtain the enthalpy for the MoW system are listed in Table 2. For the crystalline and amorphous phases in Equations (4) and (9)-(11), an entropy change of $3.5 \mathrm{~J} \mathrm{kmol}^{-1}$ was considered, owing to the disordered nature of the amorphous phase compared to the crystalline phase [33]. 
Table 2. Parameters for thermodynamic calculations in the MoW system [32,33].

\begin{tabular}{|c|c|c|c|c|c|c|}
\hline Element & $a(\mathrm{~V})$ & $n^{1 / 3} w_{\text {s }}\left(\text { d.u. }{ }^{* *}\right)^{1 / 3}$ & $G\left(10^{10} \mathrm{~N} \mathrm{~m}^{-2}\right)$ & $K\left(10^{10} \mathrm{~N} \mathrm{~m}^{-2}\right)$ & $V_{m}\left(\mathrm{~cm}^{3} \mathrm{~mol}^{-1}\right)$ & $T(\mathrm{~K})$ \\
\hline Mo & 4.65 & 1.77 & 2 & 23 & 9.33 & 2896 \\
\hline W & 4.80 & 1.81 & 1.61 & 31 & 9.47 & 3695 \\
\hline
\end{tabular}

During MA, a maximum process temperature of $473 \mathrm{~K}$ has been reported in the powder particles [34]. At this temperature, the Gibbs free energy for the solid solution and amorphous MoW phase was calculated and the results are shown in Figure 4. The results indicated that, for the crystalline solid solution, the Gibbs free energy was positive in almost all the ranges of the composition except on the interval of $x_{\mathrm{Mo}}=0.9125-1.00$ (Figure 4). This meant that, at room temperature, there was limited solubility for the formation of the MoW phase, so it required external energy for transforming the raw materials to the MoW alloy. In this work, initially $\mathrm{W}_{1.5} \mathrm{Mo}_{6} \mathrm{C}_{2.5} \mathrm{wt} . \%$ was mixed, considering only the Mo and $\mathrm{W}$ composition, and then, it was equivalent to a composition of $x_{\mathrm{o}}=0.80$ and the Gibbs free energy was $+19.82 \mathrm{~kJ} \mathrm{~mol}^{-1}$ which indicated that this phase cannot be formed at $473 \mathrm{~K}$ of temperature and atmospheric pressure because of the positive energy. Therefore, the formation of the MoW phase during the MA was associated with the use of a non-equilibrium synthesis technique which can provide extra energy of at least $349.8 \mathrm{~kJ} \mathrm{~g}^{-1}$ [30]; this caused $\Delta \mathrm{G}$ to reduce the positive energy toward the negative zone facilitating the transformation of elementary Mo and $\mathrm{W}$ powders to the MoW phase and finally the introduction of $\mathrm{C}$ in the bimetallic lattice according to the atomic size theory for the formation of interstitial solid solution [25]. As can be seen from Figure 4, the MoW crystalline phase was more stable than the amorphous phase; this was the main reason that, in the first milling times, the bcc crystalline MoW phase was formed before the amorphous phase to lead to the obtention of the bcc nanostructured MoWC.

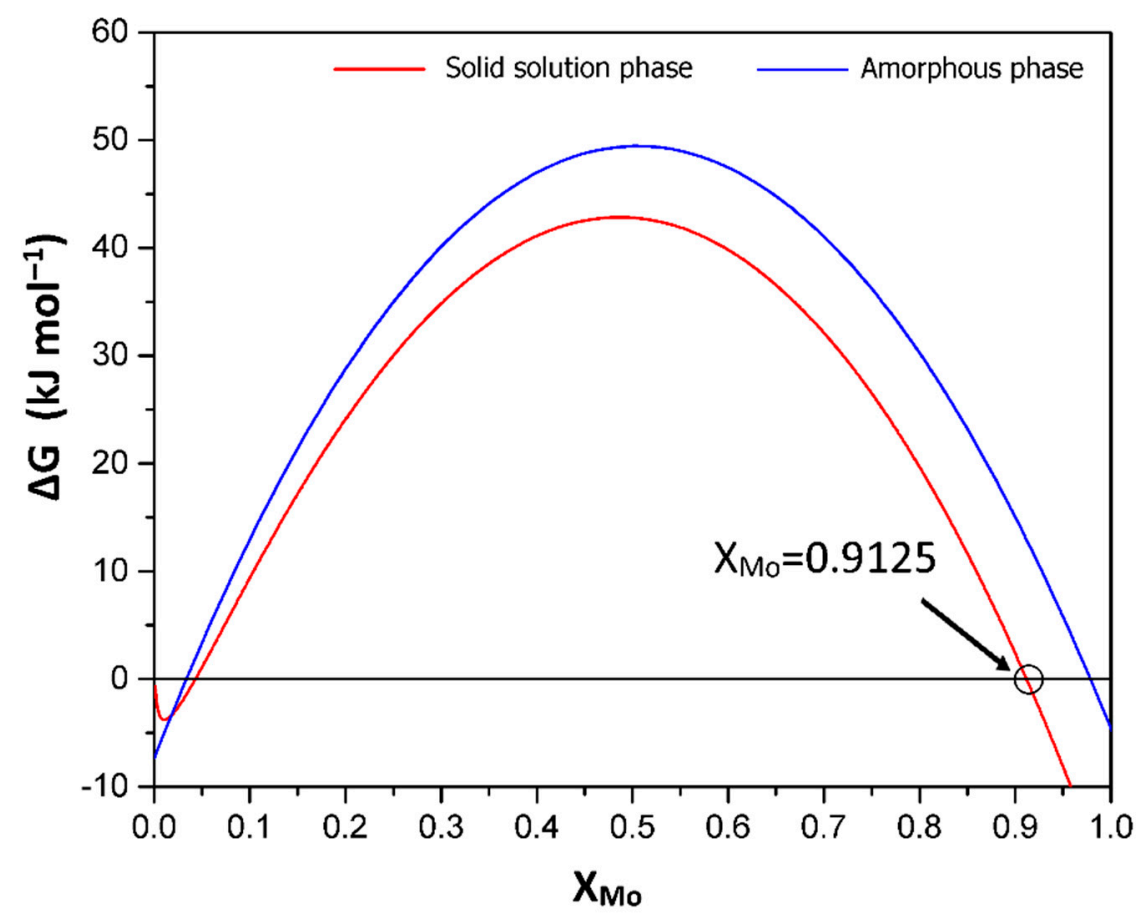

Figure 4. Gibbs free energy change for the formation of the solid solution and amorphous phase in the MoW system during mechanical alloying (MA) as calculated by Equations (9)-(11).

\subsubsection{Scanning Electron Microscopy}

Figure 5 shows the SEM images of $C$, Mo, and $W$ elemental powder particles. The average particle size calculations and the Gaussian fit distribution for the raw materials were carried out using the 
ImageJ and Origin software. The $\mathrm{C}$ particles were flake-like and their average size was approximately $6.029 \mu \mathrm{m}$ with a standard deviation (Std. Dev $(\sigma)$ ) of 2.8583. Mo and W showed a semispherical morphology with particle diameter sizes of about $15.18 \mu \mathrm{m}(\sigma=4.7581)$ and $19.41 \mu \mathrm{m}(\sigma=5.1682)$, respectively. Table 3 shows that the average size of the $C, M o$, and $\mathrm{W}$ powder particles at $0 \mathrm{~h}$ of milling was $13.54 \mu \mathrm{m}$.
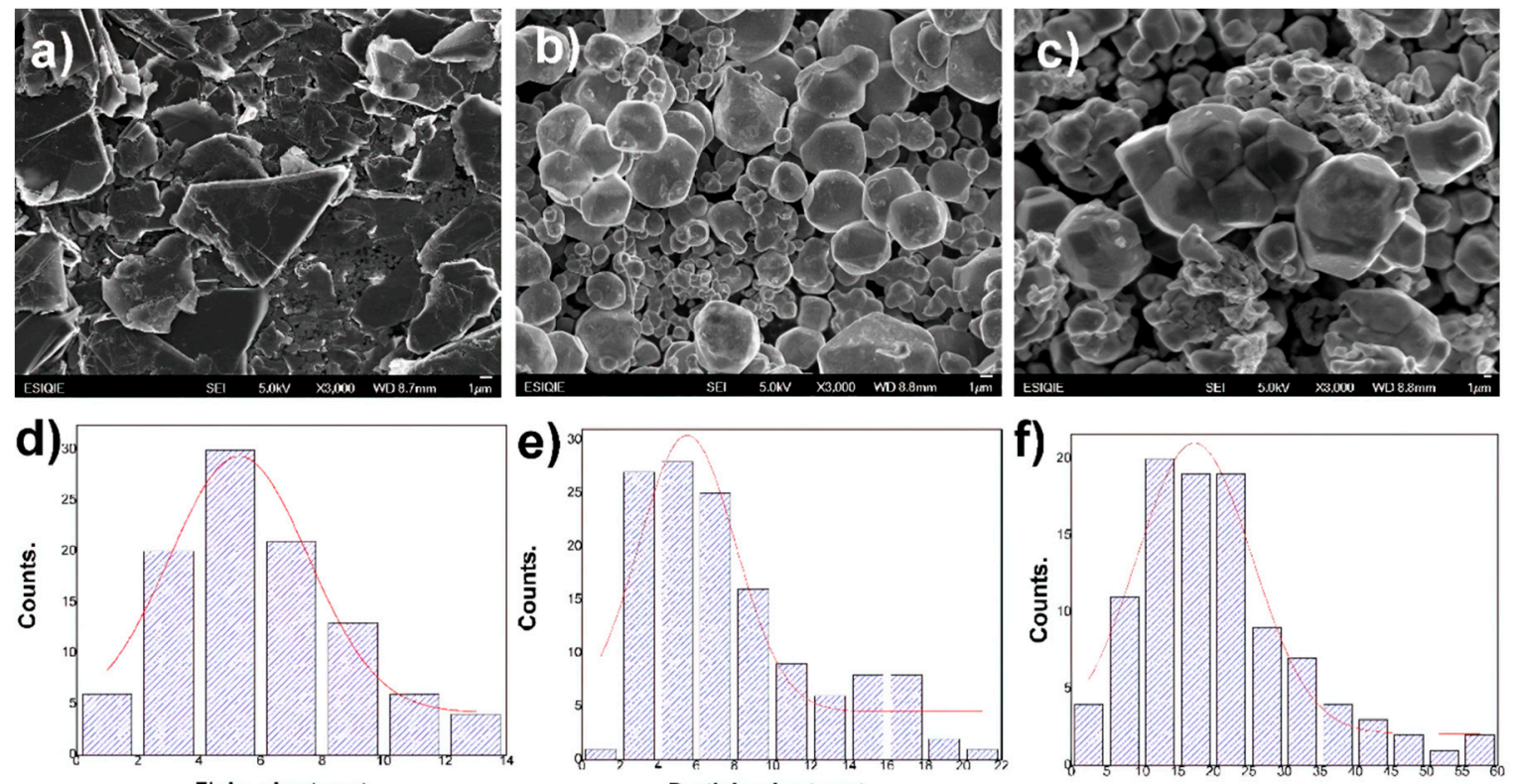

Particle size $(\mu \mathrm{m})$

Figure 5. Scanning electron microscopy (SEM) micrographs of un-milled powders particles: (a) C, (b) Mo, and (c) W. Particle size distribution histograms with Gaussian fit of (d) C flakes, (e) Mo, and (f) W particles.

Table 3. Morphological evolution parameters of the powder particles milled at high-energy MA.

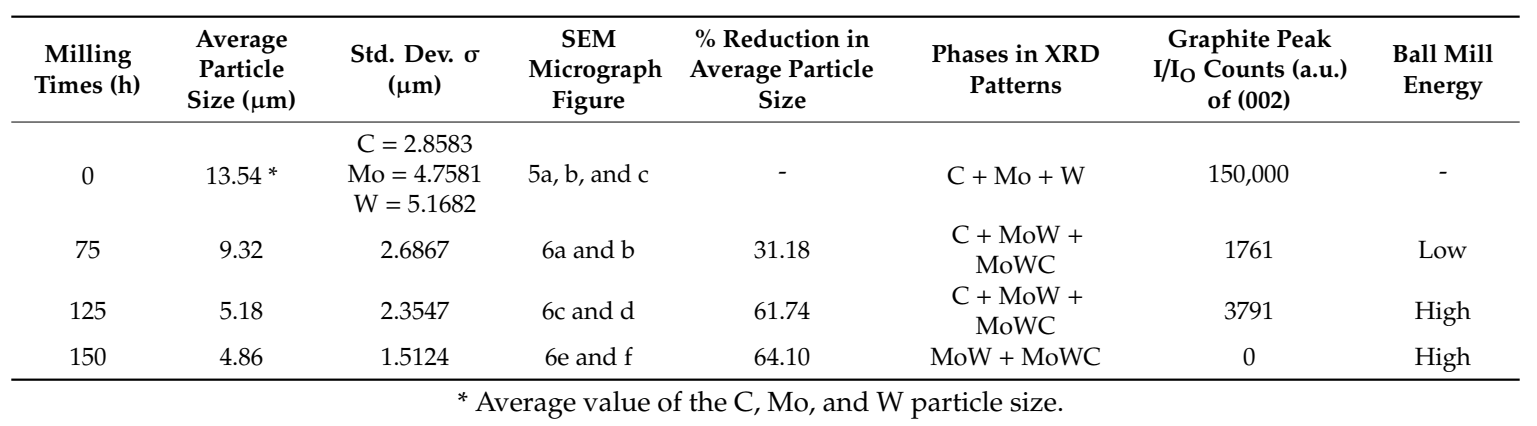

Figure 6 shows the SEM micrographs of the powders milled at 75, 125, and $150 \mathrm{~h}$. The average particle size calculations for the different milling times were made through the ImageJ software. At $75 \mathrm{~h}$ of milling (Figure $6 a, b$ ), there was a wide distribution of particle sizes. The largest particles with flake shape corresponded to the graphite phase, surrounded by smaller particles with irregular shapes corresponding to the metals. The micrographs in Figure $6 \mathrm{a}, \mathrm{b}$ showed no particles with equiaxial grains, which is a characteristic morphology of the raw materials; these particles are fractured powder particles caused by the milling process of ductile metal particles, which tends to flatten the shape of this material. At this stage of milling, the average particle size was approximately $9.32 \mu \mathrm{m}$. At $125 \mathrm{~h}$ of milling (Figure 6c,d), there was a heterogeneous size particle distribution. This type of distribution was characteristic of fracture, and this was the dominant mechanism at this stage. During MA, fracture and excision are widespread processes. The plate shapes shown in Figure 5 indicated a strong dependence of Mo's mechanical behavior and how graphite was introduced into the MoW matrix; 
the milling process repetitively exfoliates and reintegrates the powder particles, producing a thin plate morphology of about $1.3 \mu \mathrm{m}$. The $\mathrm{W}$ element's role is to harden the material and then make it brittle during the process of substitution of Mo by $W$ atoms during MA [33]. Table 3 summarizes the evolution of particle sizes related to 75,125 , and $150 \mathrm{~h}$ of milling. The table shows the average particle size of the powder particles until a value of $4.8 \mu \mathrm{m}$ for $150 \mathrm{~h}$ of milling, which was equal to a $56 \%$ reduction compared to the average size of non-milled powder particles $(0 \mathrm{~h})$ given by the commercial Mo, $\mathrm{W}$, and $\mathrm{C}$ raw materials. Table 3 also shows the intensity variation of $\mathrm{C}(002)$ which is related to introduction of $C$ into the metal lattice and the microstructural evolution at different milling stages. A decrease in the (002) peak was observed from 0 until $75 \mathrm{~h}$ of milling, but it showed an increase between 75 and $125 \mathrm{~h}$. This phenomenon was associated with a partial decomposition of graphite from the MoW alloy caused by the presence of a high density of crystalline defects, mainly, for example, dislocation and grain boundaries [17]. Then, when the milling process was continued to $150 \mathrm{~h}$, this peak vanished indicating the complete introduction of graphite into the MoW alloy to produce the MoWC solid solution. However, at $150 \mathrm{~h}$, the MoW alloy and MoWC solid solution coexisted with a composition of $27.7 \%$ and $71.3 \%$, respectively, according to XRD-Reference Intensity Ratio method (RIR) calculations [35,36].
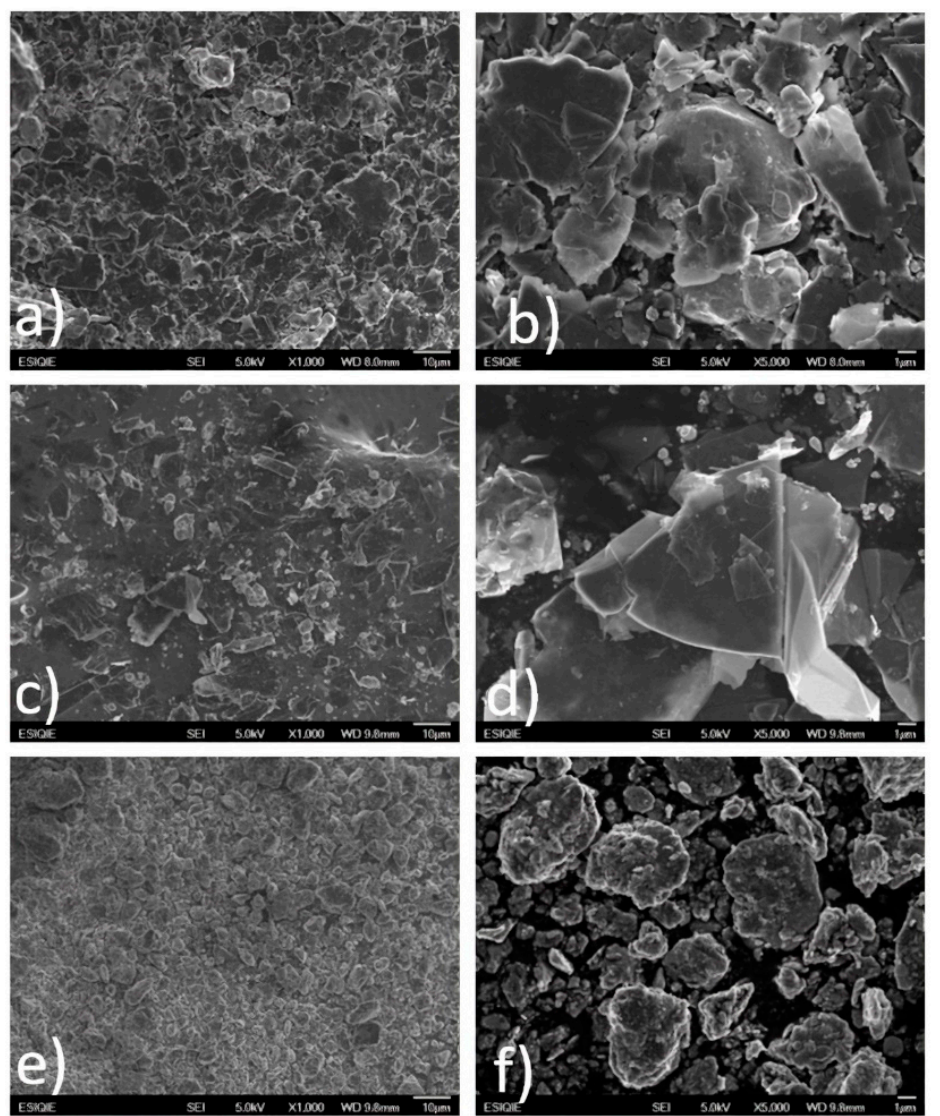

Figure 6. SEM micrographs of the powder particles milled at $75(\mathbf{a}, \mathbf{b}), 125(\mathbf{c}, \mathbf{d})$, and $150(\mathbf{e}, \mathbf{f})$ hours, showing 1000× magnification for $(\mathbf{a}, \mathbf{c}, \mathbf{e})$ and 5000× magnification for $(\mathbf{b}, \mathbf{d}, \mathbf{f})$.

According to SEM images, the raw materials showed a severe plastic deformation caused by mechanical impacts between media milling and the powder particles with repetitive fracturing during the MA process, which was the reason of the decrease in the particle size [37]. In addition, the formation of the nanostructured MoWC bimetallic carbide (Table 3) contributed to the reduction of the particle size since the existence of micro-sized carbides, that can act as grinding agents and lead to the refinement of the particle size, creates a great amount of tension energy during the milling process [38]. 
Figure 7 and Table 4 show the characteristic peaks from elemental microanalysis of the elements $\mathrm{C}, \mathrm{W}$, and Mo, as well as $\mathrm{O}, \mathrm{Fe}$, and $\mathrm{Zr}$, observed at $150 \mathrm{~h}$ of milling. O, Fe, and $\mathrm{Zr}$ phases were not detected in the XRD analysis, which indicated that only a small amount of cross contamination was obtained.

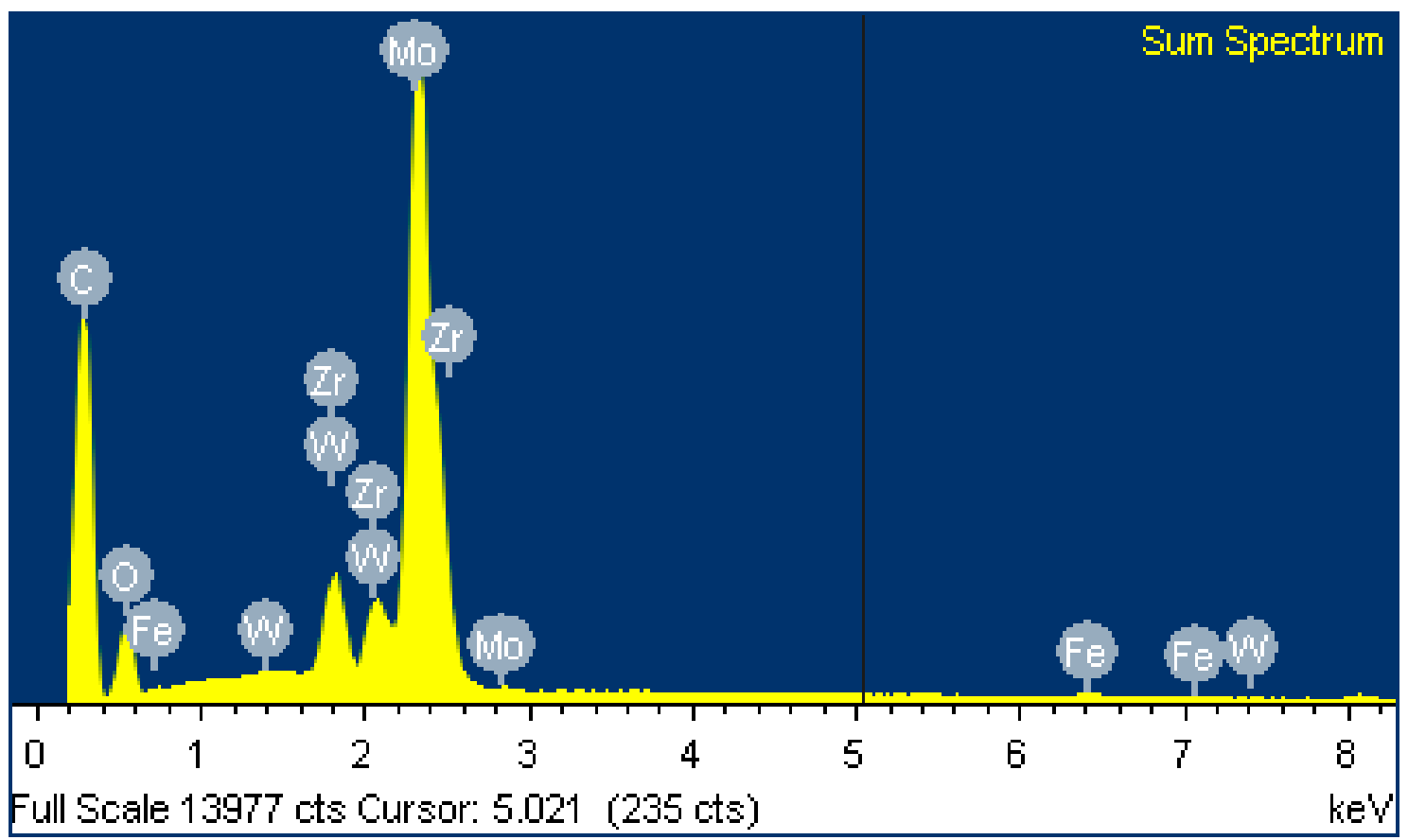

Figure 7. X-ray spectrum and semi-quantitative analysis of the milled sample at $150 \mathrm{~h}$.

Table 4. Results of semi-quantitative composition of the sample milled at $150 \mathrm{~h}$.

\begin{tabular}{cccc}
\hline Element & \%Weight & Element & \%Atomic \\
\hline C-K & 54.59 & C-K & 86.56 \\
O-K & 5.18 & O-K & 6.16 \\
Fe-K & 0.73 & Fe-K & 0.25 \\
Zr-K & 4.32 & Zr-K & 0.90 \\
Mo-K & 26.11 & Mo-K & 5.18 \\
W-K & 9.09 & W-K & 0.94 \\
\hline
\end{tabular}

To determine the distribution of the elements in the powder particles, Figure 8 shows the SEM micrographs and corresponding X-ray elemental maps obtained from SEM of the sample milled at 150 h. Figure 8 clearly shows that the sample was primarily composed of W, Mo, and C, which led to the assumption of the presence of the MoWC phase. Besides, the X-ray elemental map showed O, Fe, and $\mathrm{Zr}$ as cross contaminations that can be attributed to vial and media milling during MA. 


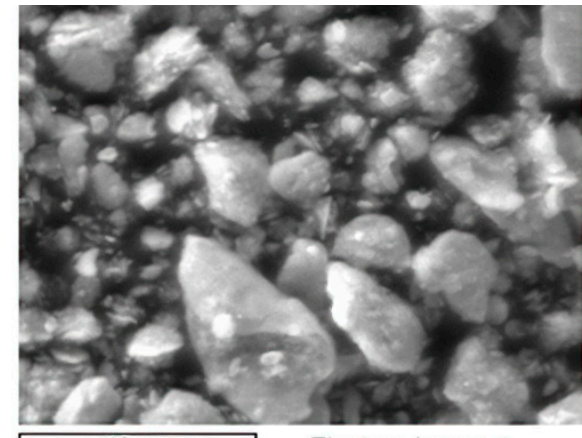

Electron Image 1

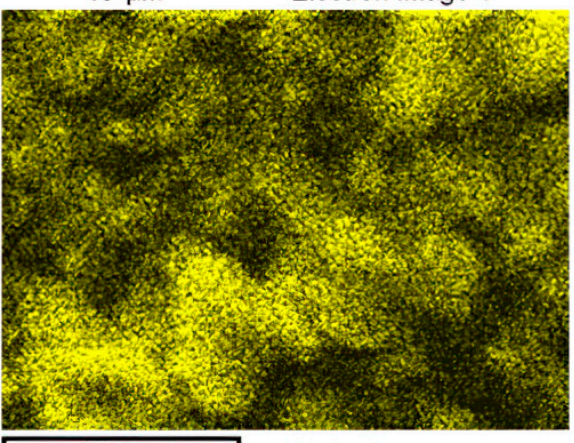

$10 \mu \mathrm{m}$

Mo La1

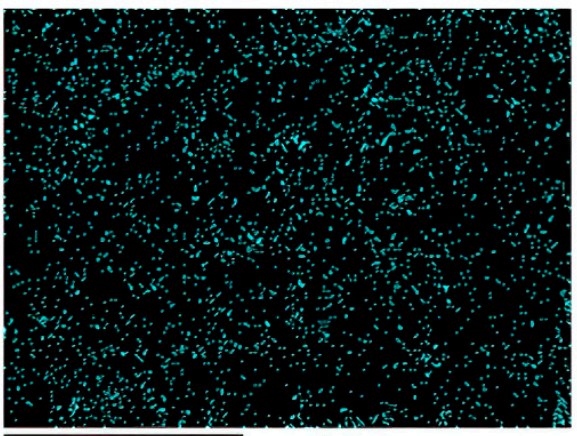

$10 \mu \mathrm{m}$

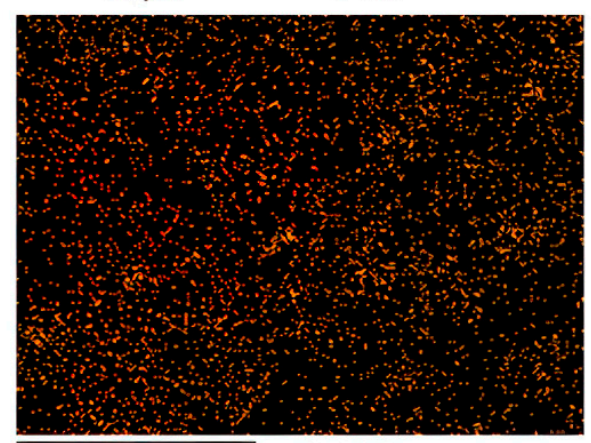

$10 \mu \mathrm{m}$

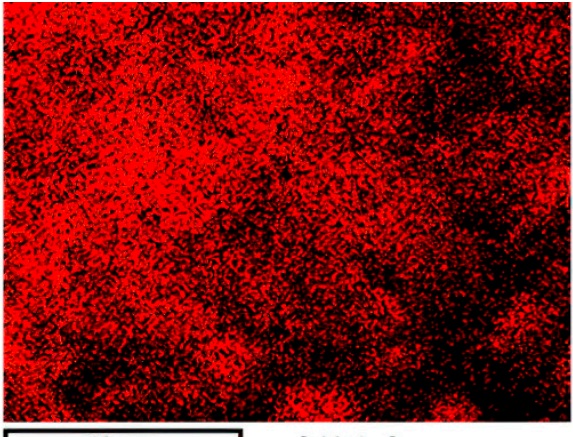

$10 \mu \mathrm{m} \longrightarrow \mathrm{CKa} 2$

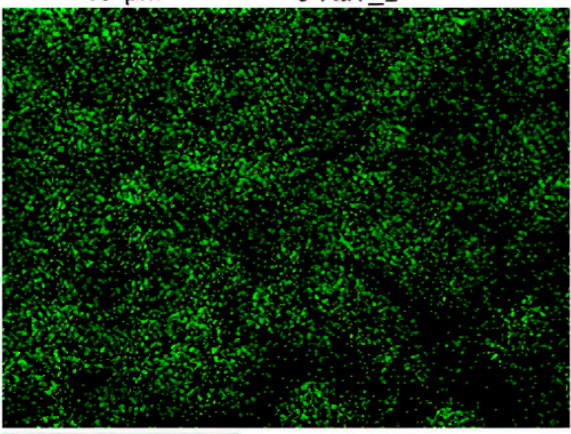

$10 \mu \mathrm{m}$

WLa1

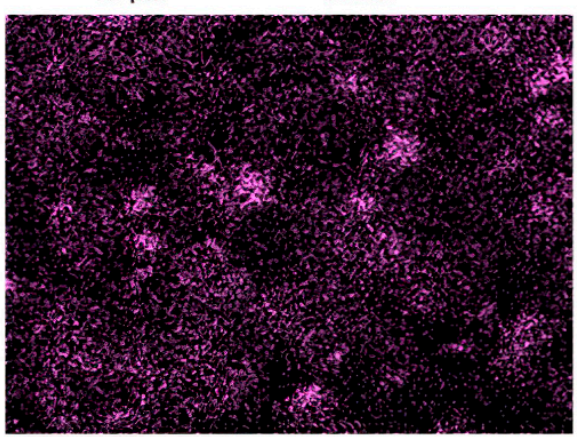

$10 \mu \mathrm{m}$

ZrLa1

Figure 8. Elemental maps showing the distribution of $\mathrm{C}, \mathrm{W}, \mathrm{Mo}, \mathrm{O}, \mathrm{Zr}$, and $\mathrm{Fe}$ of the sample during MA at $150 \mathrm{~h}$.

\subsubsection{High-Resolution Electron Microscopy}

Figure 9a shows the HRTEM micrograph of particles milled at $150 \mathrm{~h}$ with a semi-oval morphology, and the size of one of the particles was approximately $25 \mathrm{~nm}$. This particle was formed by the aggregation of smaller carbide clusters. One of these clusters was analyzed with the help of the program DigitalMicrograph. A specific area was selected to measure the interplanar spacing (d-spacing) by performing the following procedure. First, the fast Fourier transform (FFT) of the selected area was calculated (Figure 9d), and then the image was filtered with the mask command (Figure 9e). 
From Figure 9e, the high-resolution image was obtained by means of inverse Fourier transform (IFFT) (Figure 9c). In Figure 9c, the interplanar distances were calculated as seen in Figure 9b. The values obtained were $d=0.232 \mathrm{~nm}$ and $d=0.161 \mathrm{~nm}$. These values were compared with those calculated by XRD, finding a difference of $2.17 \%$; this suggested that the d-spacing measured corresponded to 110 and 200 reflections of the MoWC solid solution from the (002) zone axis, respectively. An important characteristic of the $25 \mathrm{~nm}$ particle observed in Figure 9a,c was that there was an atomic disorder, related to a short-range atomic array as in the solid solutions $[17,28]$.
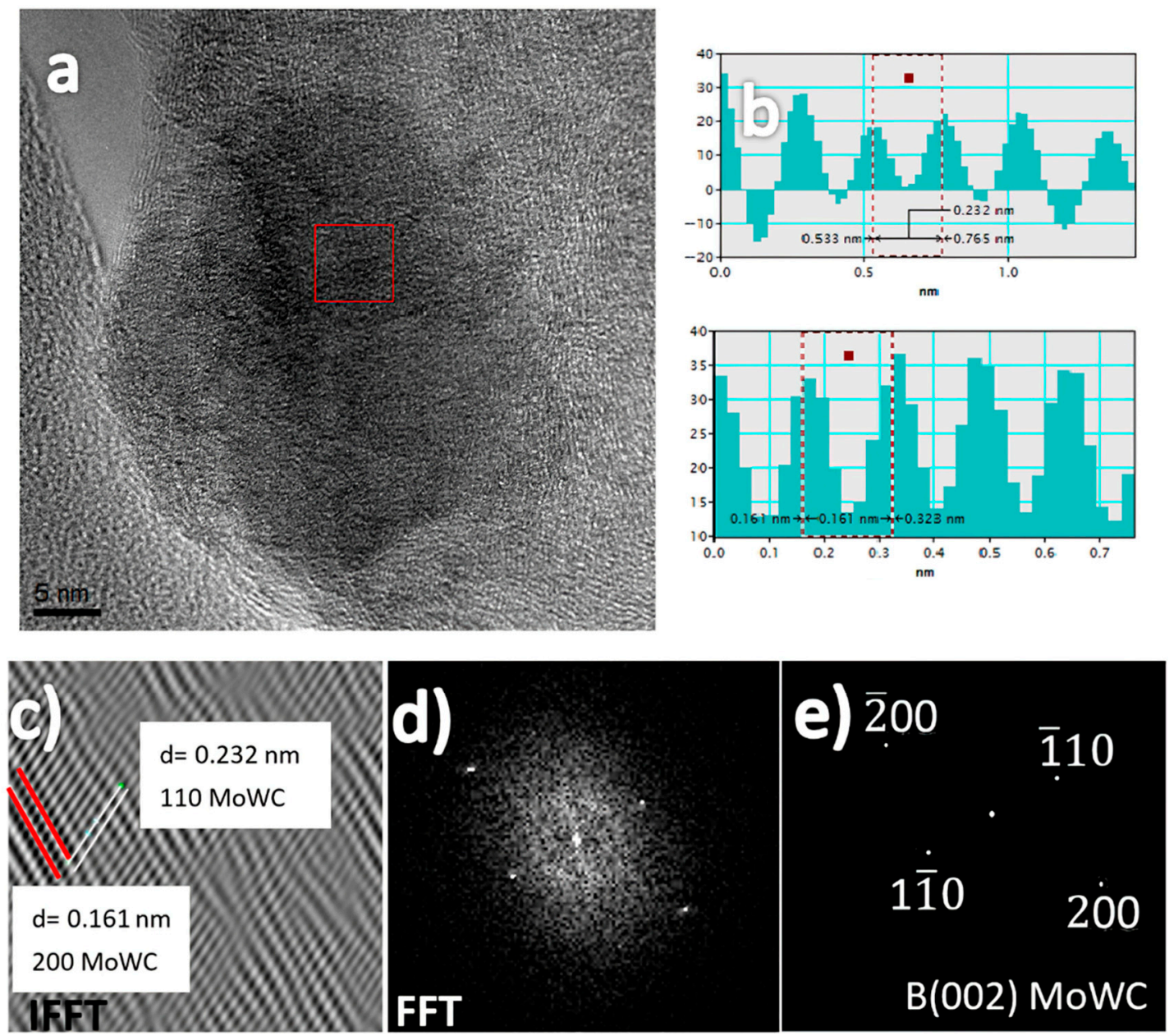

Figure 9. (a) High-resolution transmission electron microscopy (HRTEM) micrograph of a powder particle of the nanostructured MoWC system at $150 \mathrm{~h}$ of milling, (b) d-spacing measurement with the Digital Micrograph (D.M.) software, (c) Inverse fast Fourier transform (IFFT) image of the selected area, (d) simulated fast Fourier transform (FFT), and (e) FFT mask.

\subsection{Vickers Hardness}

One of the main characteristics of metallic carbides is hardness. Table 5 summarizes the average values of Vickers hardness obtained for each sample at different milling times.

Table 5 shows how hardness increased when the grinding time was increased, between 25 and $50 \mathrm{~h}$, and the hardness percent change was $27.4 \%$. From 50 to $75 \mathrm{~h}$, it grew up to $87.04 \%$ and from 75 to $125 \mathrm{~h}$, a value of $10.05 \%$ was observed. The augmentation in hardness diminished with decreasing crystal size. There are refinements of the microstructure and a high density of defects like dislocations in the powder processed by MA [7]. According to the literature, the typical carbide hardness for $\mathrm{Mo}_{2} \mathrm{C}$ shows values from 15.5 to $24.5 \mathrm{GPa}$ and for $\mathrm{W}_{2} \mathrm{C}$, the hardness value is about $22 \mathrm{GPa}$ [39]. In Table 5, the samples milled at 25 and $50 \mathrm{~h}$ showed hardness below these values. At $75 \mathrm{~h}$ of milling, hardness 
was similar to that of $\mathrm{Mo}_{2} \mathrm{C}$. At $150 \mathrm{~h}$ of milling, hardness was higher than that one of the individual carbides $\left(\mathrm{Mo}_{2} \mathrm{C}\right.$ and $\left.\mathrm{W}_{2} \mathrm{C}\right)$, which showed that a new type of carbide in a solid solution was obtained as discussed previously. The X'pert HighScore Plus software was used in order to calculate crystal size from the X-ray spectrum data. In short, hardness increased with grinding time, while crystal size decreased. The microhardness values were higher than those reported in literature [7].

Table 5. Evolution of Vickers hardness at different milling times.

\begin{tabular}{ccccc}
\hline Sample (h) & Speed (rpm) & Crystal Size (nm) & Vickers Hardness (GPa) & Vickers Std. Dev. (GPa) \\
\hline 25 & 500 & 118.3 & 10.5 & 1.1154 \\
50 & 500 & 84.1 & 13.35 & 1.1542 \\
75 & 500 & 58.7 & 24.97 & 2.0584 \\
125 & 1500 & 45.6 & 27.48 & 2.0685 \\
150 & 1500 & 40.8 & 31.48 & 2.1258 \\
\hline
\end{tabular}

\subsection{Desulfurization Properties}

Fourier transform infrared (FTIR) Spectroscopy

Figure 10 shows the infrared (IR) spectrum obtained after the aqua-thermolysis process at $200{ }^{\circ} \mathrm{C}$ of heavy crude emulsion: without sample (Figure 10a) and with sample milled at $125 \mathrm{~h}$ (Figure 10b) and $150 \mathrm{~h}$ (Figure 10c). According to the sample milled at $125 \mathrm{~h}$, a wide peak was observed at $3422 \mathrm{~cm}^{-1}$, corresponding to the hydroxy $(\mathrm{O}-\mathrm{H})$ group, which indicated that the water used reacted with the compounds in the crude oil, promoting the formation of alcohols and carboxylic acids. The strong absorption bands at $2925 \mathrm{~cm}^{-1}$ and $2856 \mathrm{~cm}^{-1}$ corresponded to saturated compounds (C-H), showing a slight increase due to hydrogenation of the unsaturated groups; this hydrogenation was caused by the Mo phase. The sample milled at $150 \mathrm{~h}$ showed an increase and widening in the peaks to $490 \mathrm{~cm}^{-1}$ and $607 \mathrm{~cm}^{-1}$, corresponding to polysulfides and disulfides, respectively. Aqua-thermolysis is a technique that can generate free radicals during the breaking of molecules; these free radicals participate in polymerization reactions, producing larger molecules [40]. There is an increase in chemical activity in desulfurization of about $15 \%$ caused by an increase in Fe in the sample. According to the literature, the increase in Fe amount can lead to increased chemical activity, as reported with a Fe content of about 0.85 at.\% [20]. The appearance of $1066 \mathrm{~cm}^{-1}$ peak suggested that the reaction led to chain breakage, but then were polymerized, forming larger polysulfide molecules. This phenomenon indicated the desulfurization of heavy oil by the sample milled at $150 \mathrm{~h}$, but then a polymerization reaction was observed after the aqua-thermolysis process. For both samples, there was a loss of peak intensity at $822 \mathrm{~cm}^{-1}$, corresponding to the group $\mathrm{C}=\mathrm{C}$; this can be attributed to three factors: (1) hydration of alkenes-water is added to the double bond forming alcohols, (2) hydrogenation of alkenes-hydrogen is added to the double bond forming saturated compounds, and (3) breakage of double bonds [41]. One event that is always present in MA synthesis is the cross contamination in samples, usually of Fe due to wear and tear of the milling tools. If the proposal of using MoWC material is for catalysis during the aqua-thermolysis of heavy oil, the presence of Fe can interact with asphaltenes causing the reduction of the strength of the C-C, C-N, and C-S bonds. Therefore, it is an element commonly used in the synthesis of catalysts for hydrodesulfurization, such as hematite $\left(\mathrm{Fe}_{2} \mathrm{O}_{3}\right)$, which shows excellent catalytic activity in reducing the viscosity of heavy oil $[37,42]$. Figure 8 shows the distribution of the elemental SEM maps. The distribution showed that these particles were mainly composed of carbon and molybdenum, with a small contribution of tungsten, demonstrating the presence of the nanostructured MoW bimetallic carbide in a solid solution under X-ray results. 


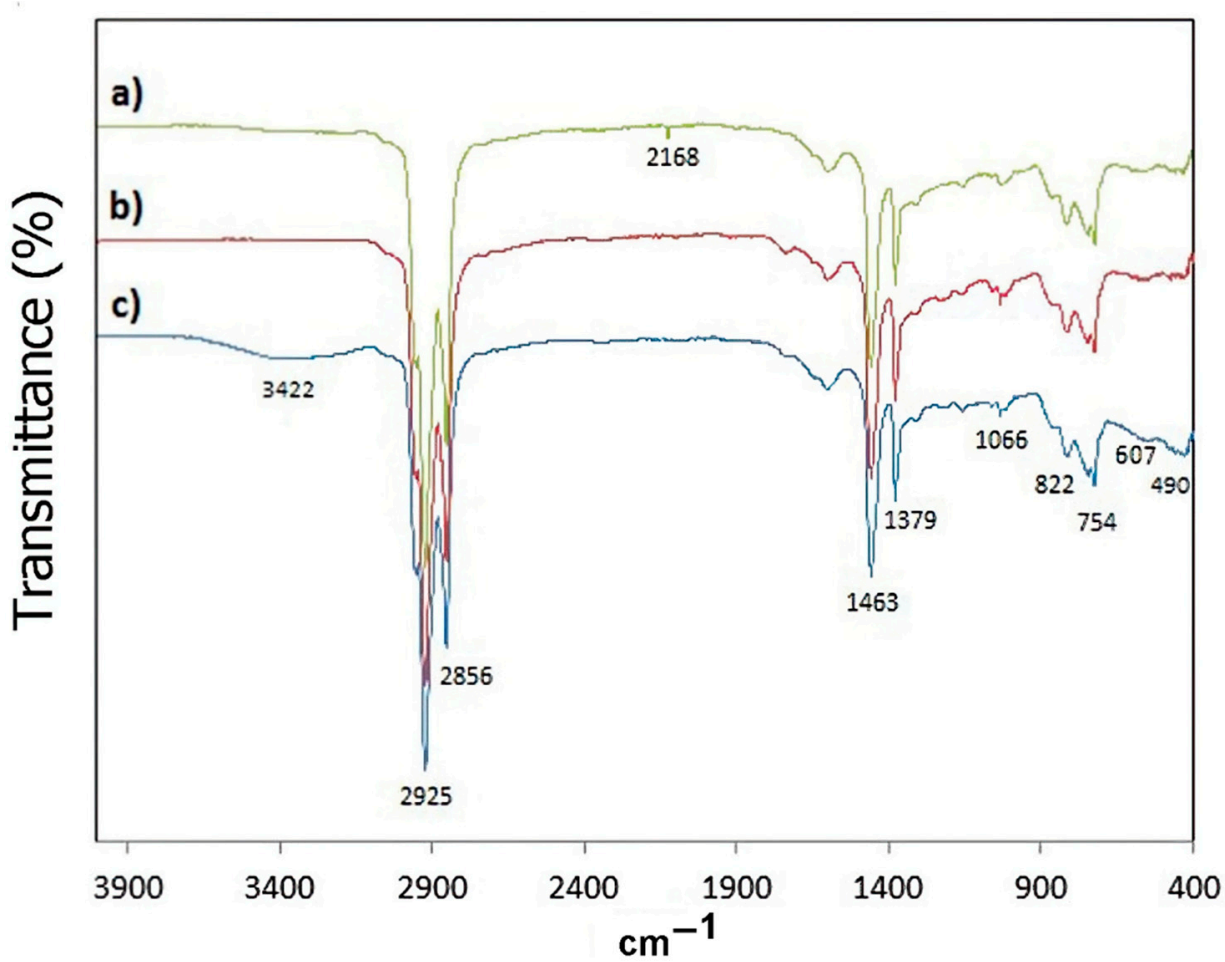

Figure 10. Infrared (IR) spectrum of extra-heavy crude oil during aqua-thermolysis at $200{ }^{\circ} \mathrm{C}$, (a) without the catalyst, and with catalysts milled at (b) $125 \mathrm{~h}$ and (c) $150 \mathrm{~h}$.

\section{Conclusions}

Nanostructured WMo and $\mathrm{WmoC}$ phases were successfully synthesized by MA with a crystal size of $40.8 \mathrm{~nm}$ after $150 \mathrm{~h}$ with the nominal composition $\mathrm{W}_{1.5} \mathrm{Mo}_{6} \mathrm{C}_{2.5} \mathrm{wt} . \%$. WMoC was a bcc crystalline structure with a lattice parameter (a) of $0.3148 \mathrm{~nm}$. The WMo crystalline structure was bcc with a lattice parameter (a) of $0.315 \mathrm{~nm}$. This system was a nanostructured solid solution of WMo and WMoC phases. At the first stage of milling, the $\mathrm{W}$ atoms substituted the Mo atoms, producing the MoW alloys with a bcc crystalline structure and a lattice parameter size closer to that of Mo, and then during the last stage of milling, the $\mathrm{C}$ atoms were introduced to the interstitial position of the bimetallic MoW alloy matrix without distorting the lattice. According to the Miedema model, in the MoW system, the formation of the MoW phase during the MA was associated with using a non-equilibrium synthesis technique that can provide extra energy. Further research is required to understand the transformation from MoW to MoWC ternary system by Miedema model calculations. The Vickers hardness of the material increased as the nanostructured metallic carbide in the solid solution was formed by increasing the milling time. This mechanical mixing showed a high microhardness value compared with other monometallic carbide materials. The microstructure, hardness, and desulfurization properties of the MoWC phase were totally dependent on the particle size and grinding time. The samples synthesized at 125 and $150 \mathrm{~h}$ of milling showed a reduction of sulfur molecules at $200^{\circ} \mathrm{C}$. However, these samples did not show hydrogenation or the production of lighter chains of compounds caused by a polymerization process, maybe because the emulsion required a higher temperature for optimal activation. There was an increase in chemical activity in desulfurization of about $15.6 \%$ caused by an increase in Fe in the sample, possibly because it needs a ferromagnetic material presence. The chemical activity of a catalyst depends on its electric mobility; in this paper, the catalyst was a diamagnetic carbide, which can show repulsion caused by the ferromagnetic metals (like Fe), thus forming an electric current, and then, the presence of Fe activates the chemical activity of this material. Even though the chemical activity of the samples did not present high percentages of desulfurization or hydrogenation, this experiment served to show the importance of adding chemical activators to the carbide samples in the aqua-thermolysis process. 
These chemical activators must have a ferromagnetic behavior, or have an energy out of equilibrium, high enough to guarantee high rates of hydrogenation and desulfurization as observed in the reference; catalyst leaching and reusability for the removal of oil should be the subject of future studies.

Author Contributions: Conceptualization, M.M.R. and L.G.D.B.A.; methodology, J.N.R.O. and L.G.D.B.A.; HRTEM visualization, V.G.F.; investigation, J.N.R.O.; XRD, IR, Vickers analysis, L.G.D.B.A. and M.M.R.; writing-review and editing, R.M.D. and L.G.R.; thermodynamic analysis, J.N.R.O. and J.G.M. All authors have read and agreed to the published version of the manuscript.

Funding: This research was funded by projects TECNM-8207.20-PD and IPN-2020.

Acknowledgments: The authors thank CONACyT for its distinction and encouragement through the national researcher program S.N.I. J.N.R.O. and J.G.M. thank TESI for the financial support and SEP-PRODEP for the research work TECNM-CA-TESI Materiales Nanoestruturados.

Conflicts of Interest: The authors declare no conflict of interest.

\section{References}

1. Theofanidis, S.A.; Galvita, V.V.; Konstantopoulos, C.; Poelman, H.; Marin, G.B. Fe-based nano-materials in catalysis. Materials 2018, 11, 831. [CrossRef] [PubMed]

2. Kalita, D.; Chetia, L.; Ahmed, G.A. Synthesis of MoW-Sulfide compound nanoparticles as a photocatalyst and comparison of its performance with $\mathrm{MoS}_{2}$ and $\mathrm{WS}_{2}$ nanoparticles. J. Environ. Chem. Eng. 2017, 5, 3161-3171. [CrossRef]

3. Olvera, J.N.R.; Gutiérrez, G.J.; Serrano, J.A.R.; Ovando, A.M.; Febles, V.G.; Arceo, L.D.B. Use of unsupported, mechanically alloyed NiWMoC nanocatalyst to reduce the viscosity of aquathermolysis reaction of heavy oil. Catal. Commun. 2014, 43, 131-135. [CrossRef]

4. Villasana, Y.; Méndez, F.J.; Luis-Luis, M.; Brito, J.L. Pollutant reduction and catalytic upgrading of a Venezuelan extra-heavy crude oil with $\mathrm{Al}_{2} \mathrm{O}_{3}$-supported $\mathrm{NiW}$ catalysts: Effect of carburization, nitridation and sulfurization. Fuel 2019, 235, 577-588. [CrossRef]

5. Díaz de León, J.N.; Castañeda-García, A.L.; Soto-Arteaga, C.E.; Torres-Otañez, G.; Esqueda-Barrón, Y.; Guzmán-Cruz, M.A.; Alonso-Nuñez, G.; Fuentes-Moyado, S. Selective removal of sulfur from 3-methyl thiophene under mild conditions over $\mathrm{NiW} / \mathrm{Al}_{2} \mathrm{O}_{3}-\mathrm{TiO}_{2}$ modified by surfactants. Catal. Today 2020. [CrossRef]

6. Guo, T.; Huang, P.; Wang, F. Unusual high strain rate sensitivity of amorphous/crystalline NiW composites. Mater. Lett. 2019, 248, 189-192. [CrossRef]

7. Rivera Olvera, J.N.; Gutiérrez Paredes, G.J.; Romero Serrano, A.; Rivera López, E.; Martínez Franco, E.; Tamayo Meza, P.; Díaz Barriga Arceo, L. Synthesis and characterization of a MoWC-WC-NiC nanocomposite via mechanical alloying and sintering. Powder Technol. 2015, 271, 292-300. [CrossRef]

8. Li, B.; Zhang, W.; Li, D.; Wang, J. Electrodeposition of $\mathrm{Ni}[\mathrm{sbnd}] \mathrm{W} / \mathrm{ZrO}_{2}$ nanocrystalline film reinforced by $\mathrm{CeO}_{2}$ nanoparticles: Structure, surface properties and corrosion resistance. Mater. Chem. Phys. 2019, 229, 495-507. [CrossRef]

9. Ashenaeian, S.; Haghighi, M.; Rahemi, N. Hybrid plasma-sono-coprecipitation dispersion of NiMo nanocatalyst over functionalized multiwall carbon nanotube used in hydrodesulfurization of thiophene. Adv. Powder Technol. 2019, 30, 502-512. [CrossRef]

10. Wu, Z.M.; Liang, Y.X.; Fu, E.G.; Du, J.L.; Wang, P.P. The process and mechanisms for the transformation of coarse grain to nanoscale grain in tungsten by ball milling. Powder Technol. 2018, 326, 222-227. [CrossRef]

11. Chen, Q.; Liang, S.; Zhang, J.; Zhang, X.; Wang, C.; Song, X.; Zhuo, L. Preparation and characterization of WMo solid solution nanopowders with a wide composition range. J. Alloys Compd. 2020, 823, 153760. [CrossRef]

12. González, G.; Sagarzazu, A.; Villalba, R.; Ochoa, J. Comparative study of NiW, NiMo and MoW prepared by mechanical alloying. J. Alloys Compd. 2007, 434-435, 525-529. [CrossRef]

13. Gonzalez, G.; Sagarzazu, A.; Bonyuet, D.; D’Angelo, L.; Villalba, R. Solid state amorphisation in binary systems prepared by mechanical alloying. J. Alloys Compd. 2009, 483, 289-297. [CrossRef]

14. Ren, C.; Fang, Z.Z.; Koopman, M.; Butler, B.; Paramore, J.; Middlemas, S. Methods for improving ductility of tungsten-A review. Int. J. Refract. Met. Hard Mater. 2018, 75, 170-183. [CrossRef]

15. Ohser-Wiedemann, R.; Martin, U.; Müller, A.; Schreiber, G. Spark plasma sintering of Mo-W powders prepared by mechanical alloying. J. Alloys Compd. 2013, 560, 27-32. [CrossRef] 
16. Díaz Barriga, L.; González, L.; Rivera, O.J.N.; Medina, O.; Garibay, V. Intercalated intermetallic compounds $\mathrm{AlTi}_{3}$ and $\mathrm{Fe}_{2} \mathrm{Ti}$ in microrods and microtubes obtained by invariant reaction of mechanically milled system $\mathrm{Al}_{43} \mathrm{Ti}_{36} \mathrm{Fe}_{21}$. Materials 2019, 12, 3086. [CrossRef]

17. Suryanarayana, C. Mechanical Alloying and Milling; CRC Press: NewYork, NY, USA, 2004; pp. 22-25. ISBN 9780203020647.

18. Intrater, J. Mechanical Alloying and Milling: A book review. Mater. Manuf. Process. 2007, 22, 790-791. [CrossRef]

19. Zaara, K.; Chemingui, M.; Gallet, S.L.; Gaillard, Y.; Escoda, L.; Saurina, J.; Suñol, J.J.; Bernard, F.; Khitouni, M.; Optasanu, V. High-entropy feconib ${ }_{0.5} \mathrm{si}_{0.5}$ alloy synthesized by mechanical alloying and spark plasma sintering. Crystals 2020, 10, 929. [CrossRef]

20. Wang, Y.; Chen, Y.; He, J.; Li, P.; Yang, C. Mechanism of catalytic aquathermolysis: Influences on heavy oil by two types of efficient catalytic ions: $\mathrm{Fe}^{3+}$ and $\mathrm{Mo}^{6+}$. Energy Fuels 2010, 24, 1502-1510. [CrossRef]

21. Hu, Y.; Jia, G.; Ma, S.; Hu, J.; Zhu, P.; Cui, T.; Li, Z.; Zou, Z. Hydrogen evolution reaction of $\gamma-\mathrm{Mo}_{0.5} \mathrm{~W}_{0.5} \mathrm{C}$ achieved by high pressure high temperature synthesis. Catalysts 2016, 6, 208. [CrossRef]

22. Ma, S.; Bao, K.; Tao, Q.; Huang, X.; Zhu, P.; Cui, T. An ultra-incompressible ternary transition metal carbide. RSC Adv. 2014, 4, 63544-63548. [CrossRef]

23. Toth, L. Transition Metal Carbides and Nitrides, 1st ed.; Academic Press, Inc.: Cambridge, MA, USA, 1971; ISBN 9780323157223.

24. Mousavi, T.; Abbasi, M.H.; Karimzadeh, F. Thermodynamic analysis of NiTi formation by mechanical alloying. Mater. Lett. 2009, 63, 786-788. [CrossRef]

25. Pierson, H.O. Handbook of Refractory Carbides and Nitrides: Properties, Characteristics, Processing, and Applications; Noyes Publication: Westwood, NJ, USA, 1996; ISBN 9780815513926.

26. Suryanarayana, C.; Grant, N.M. X-rays and Diffraction: A Practical Approach; Springer: New York, NY, USA, 1998; ISBN 9781489901484.

27. Askeland, D.; Fulay, P.; Wright, W. The Science \& Engineering of Materials; Thomson: Stamford, CT, USA, 2010; ISBN 0495296023.

28. Nishizawa, T. Thermodyn. Microstruct; ASM International: Geauga, OH, USA, 2008; ISBN 1615031286.

29. Cottrell, S.A. An Introduction to Metallurgy, 2nd ed.; Edward Arnold Publisher: London, UK, 1995; ISBN 0901716936.

30. Torkan, S.; Ataie, A.; Abdizadeh, H.; Sheibani, S. Effect of milling energy on preparation of nano-structured $\mathrm{Fe}_{70} \mathrm{Si}_{30}$ alloys. Powder Technol. 2014, 267, 145-152. [CrossRef]

31. Ray, P.K.; Akinc, M.; Kramer, M.J. Applications of an extended Miedema's model for ternary alloys. J. Alloys Compd. 2010, 489, 357-361. [CrossRef]

32. Rivera Olvera, J.N.; Acevedo Martínez, J.; Herrera Hernández, H.; García Orozco, I.; Díaz Barriga Arceo, L. Microstructural characterization and thermodynamic analysis of MoZn produced by mechanical alloying. J. Alloys Compd. 2017, 696, 329-337. [CrossRef]

33. De Boer, F.R.; Boom, R.; Mattens, W.C.M.; Miedema, A.R.; Niessen, A.K. Cohesion in Metals: Transition Metal Alloys; North-Holland Editorial: Amsterdam, The Netherlands, 1989; ISBN 0444870989.

34. Al-Joubori, A.A.; Suryanarayana, C. Synthesis of metastable $\mathrm{NiGe}_{2}$ by mechanical alloying. Mater. Des. 2015, 87, 520-526. [CrossRef]

35. Bermudez-Polonio, J. Métodos de Difraccion de Rayos X: Principios y Aplicaciones; Piramide Editorial: Madrid, Spain, 1981; ISBN 9781624102141.

36. Cullity, B.D.; Stock, S.R. Elements of X-ray Diffraction, 3rd ed.; Prentice Hall: New York, NY, USA, 2001; ISBN 0201610914.

37. Martínez, C.; Aguilar, C.; Briones, F.; Guzmán, D.; Zelaya, E.; Troncoso, L.; Rojas, P.A. Effects of Zr on the amorphization of Cu-Ni-Zr alloys prepared by mechanical alloying. J. Alloys Compd. 2018, 765, 771-781. [CrossRef]

38. Chen, C.L. Suprianto investigation of W-Ti ODS coating on SUS304 steel fabricated by mechanical alloying technique. Surf. Coatings Technol. 2018, 350, 1105-1111. [CrossRef]

39. Dorfman, M.R. Thermal spray materials. Adv. Mater. Process. 2002, 160, 49-51.

40. Li, C.; Huang, W.; Zhou, C.; Chen, Y. Advances on the transition-metal based catalysts for aquathermolysis upgrading of heavy crude oil. Fuel 2019, 257, 115779. [CrossRef] 
41. Wu, C.; Lei, G.L.; Yao, C.J.; Gai, P.Y.; Cao, Y.B.; Li, X.N. Mechanism for reducing the viscosity of extra-heavy oil by aquathermolysis with an amphiphilic catalyst. J. Fuel Chem. Technol. 2010, 38, 684-690. [CrossRef]

42. Jung, Y.; Stevens, E.; Ding, B.; Kim, S.D.; Woo, S.K.; Lee, J.K. Microstructure and electrical conductivity in shape and size controlled molybdenum particle thick film. J. Mater. Sci. 2013, 48, 3760-3768. [CrossRef]

Publisher's Note: MDPI stays neutral with regard to jurisdictional claims in published maps and institutional affiliations.

(C) 2020 by the authors. Licensee MDPI, Basel, Switzerland. This article is an open access article distributed under the terms and conditions of the Creative Commons Attribution (CC BY) license (http://creativecommons.org/licenses/by/4.0/). 